Colorectal cancer (CRC) is one of the most common malignancies in the world. Each year one million new cases are diagnosed and about 500000 people die of this disease. Due to the development of research in clinical oncology, many new antineoplastic agents are registered and available in the treatment of CRC, for example irinotecan, oxaliplatin, 5-fluorouracil, capecitabine, and the monoclonal antibodies bevacizumab, panitumumab and cetuximab. Introduction of molecularly targeted therapies caused prolongation of median time to progression of the disease as well as median overall survival. The best sequence of the therapeutic options for the achievement of the patients' benefits and good tolerance of the treatment has not been established. This article contains a review of randomized phase II/III studies and registration trials regarding systemic treatment of CRC. The authors have attempted to translate the results of the studies into treatment optimization.

Key words: colorectal cancer, palliative chemotherapy, bevacizumab, panitumumab, cetuximab.

\section{Optimal chemotherapy treatment for patients with advanced colorectal cancer}

Rafał Stec ${ }^{1}$, Lubomir Bodnar ${ }^{1}$, Marta Smoter ${ }^{1}$, Michał Mączewski², Cezary Szczylik

1Department of Oncology, Military Institute of Health Services, Warsaw, Poland 2Department of Clinical Physiology, Medical Center of Postgraduate Education, Warsaw, Poland

\section{Introduction}

Colorectal cancer (CRC) is one of the most common malignancies in the world. Each year one million new cases are diagnosed and about 500000 people die of this disease [1]. Approximately 14000 new cases are diagnosed annually in Poland. Incidence of colorectal cancer increases with age, starting from the age of 40 , with a rapid increase after the age of $50[2,3]$.

Most colorectal cancer patients (50-60\%) have stage IV disease at the time of first diagnosis [4]. Palliative systemic therapy that offers a possibility of prolonged survival and improved quality of life is one of the possible therapeutic options for these patients.

Due to the development of research in clinical oncology, many new antineoplastic agents are registered and available in the treatment of CRC, for example irinotecan, oxaliplatin, 5-fluorouracil, capecitabine, and the monoclonal antibodies bevacizumab, panitumumab and cetuximab.

The most important challenge in CRC treatment is treatment optimization, which should combine maximum effectiveness with the lowest possible toxicity. Currently there is an ongoing search for new biomarkers that could be helpful in proper selection of therapies for patients. Some of them have already been introduced to routine practice, while others are still in the development phase and their clinical utility must be confirmed.

Currently, according to NCCN recommendations, patients with advanced CRC are classified into two categories: patients in good general condition, without significant comorbidities, who may be eligible for intensive palliative therapy (e.g. intensive chemotherapy), and patients in worse general condition, with significant comorbidities, for whom more conservative management is recommended [e.g. best supportive care (BSC) or less intensive chemotherapy: capecitabine monotherapy, 5-fluorouracil with leucovorin and possibly monoclonal antibodies - bevacizumab, panitumumab or cetuximab].

Patients with worse performance status, with multiple comorbidities, can be qualified for systemic treatment that carries lower risk of side effects.

Introduction of multi-drug chemotherapy in combination with "targeted" therapy in the treatment of advanced CRC led to a situation where patient classification according to lesion resectability became as important. There are three categories of patients: patients with primary resectable metastases; patients who may be eligible for surgical resection of metastases following aggressive systemic therapy; and patients unlikely to ever undergo resection of metastases.

The aim of this paper is to review randomized phase II and III studies of CRC systemic therapy and to attempt to translate the results of these studies into optimization of the therapeutic approach. 


\section{Irinotecan and oxaliplatin as first line of treatment of metastatic colorectal cancer}

\section{Irinotecan}

Irinotecan (CPT-11) is a semi-synthetic derivative of an alkaloid obtained from the tree Camptotheca acuminata. CPT-11 belongs to a group of cytostatics that exhibit antitumour activity mainly through inhibition of topoisomerase I. Slight contribution to CPT-11 activity is also attributed to induction of endonucleases and serine proteases. CPT-11 undergoes conversion to an active tissue metabolite, SN-38, that is predominantly responsible for antitumour activity. It belongs to phase-specific agents, which is related to their activity in phase $\mathrm{S}$ of the cell cycle, when topoisomerase I activity in the nucleus is highest [5].

One of the regimens containing irinotecan used in the palliative treatment of CRC is a three-drug regimen, irinotecan, 5-fluorouracil and leucovorin, administered in various combinations (e.g. regimen FOLFIRI, IFL).

Based on conducted multicentre, randomized clinical trials, high effectiveness of the irinotecan-based three-drug regimen was confirmed versus the two-drug leucovorin and 5-fluorouracil based regimen (LF "Mayo Clinic" regimen) as first line therapy of metastatic CRC. A study by Saltz et al. demonstrated a $50 \%$ objective response rate for the irinotecan regimen (IFL regimen) vs. $28 \%(p<0.001)$, median time to progression 7.0 vs. 4.3 months $(p=0.004)$ and median overall survival 14.8 vs. 12.6 months $(p=0.04)$ [6].

Douillard et al. in another multicentre, randomized clinical trial, after treatment with an irinotecan-based regimen ("weekly" or "biweekly" regimen, depending on the study site) achieved $49 \%$ vs. $31 \%$ response $(p<0.001)$ in patients treated with leucovorin and 5-fluorouracil, median time to progression was 6.7 vs. 4.4 months ( $p<0.001)$, and median overall survival was 17.4 vs. 14.1 months $(p=0.031)$ [7].

Retrospective analysis by Gluzman et al. [8] compared the effects of IFL (day 1: irinotecan $125 \mathrm{mg} / \mathrm{m}^{2}$, leucovorin $20 \mathrm{mg} / \mathrm{m}^{2}, 5$-fluorouracil $500 \mathrm{mg} / \mathrm{m}^{2}$ administered every 7 days for 4 consecutive weeks, in 6-week cycles) and FOLFIRI (day 1: irinotecan $180 \mathrm{mg} / \mathrm{m}^{2}$, leucovorin $200 \mathrm{mg} / \mathrm{m}^{2}$ intravenous infusion over 2 hours, 5 -fluorouracil $400 \mathrm{mg} / \mathrm{m}^{2}$ "bolus" and 46-hour intravenous 5-fluorouracil infusion 2400$3000 \mathrm{mg} / \mathrm{m}^{2}$ in 14-day cycles). The authors observed prolongation of median time free from progression in the second arm of the study (9.4 months vs. 6 months for the group treated with the IFL regimen). However, no prospective, randomized study is available that would directly compare both these

Table 1. Efficacy of irinotecan- and oxaliplatin-based chemotherapy

\begin{tabular}{|lcc|}
\hline Chemotherapy regimen & CLF & FOLFOX \\
\hline OR (CR + PR) (\%) & $49[7]$ & $50.7[10]$ \\
& $50[6]$ & \\
median time to progression & $6.7[7]$ & $9.0[10]$ \\
(months) & $7.0[6]$ & \\
\hline median overall survival (months) & $17.4[7]$ & $16.2[10]$ \\
& $14 .[6]$ & \\
\hline
\end{tabular}

$C L F-$ irinotecan + 5-fluorouracil + leucovorin

FOLFOX - oxaliplatin + 5-fluorouracil + leucovorin irinotecan-based regimens. Therefore it is unknown which of these two regimens is more active as first line therapy for metastatic CRC.

\section{Oxaliplatin}

Oxaliplatin is a platinum-based (third generation) antitumour agent, containing a platinum atom complexed with cyclohexane-1,2-diamine and an oxalate group (chemical name: (SP-4-2)[(1R,2R)-cyclohexane-1,2-diamine- $\kappa(2) \mathrm{N}, \mathrm{N}$ ] [ethanedioato(2-)-kappa(2)O(1),O(2)]platinum). Its mechanism of action involves formation of bonds between and inside DNA strands and abnormal DNA molecules and inhibition of DNA, RNA and protein synthesis [9].

Activity of oxaliplatin as first line treatment of metastatic CRC was confirmed by De Gramont et al. [10] in a paper published in 2000. In a group of patients receiving oxaliplatin (FOLFOX 4 regimen) (day 1: oxaliplatin $85 \mathrm{mg} / \mathrm{m}^{2}$, leucovorin $100 \mathrm{mg} / \mathrm{m}^{2}$ 2-hour intravenous infusion, 5-fluorouracil $400 \mathrm{mg} / \mathrm{m}^{2}$ "bolus" and 22-hour 5-fluorouracil intravenous infusion $600 \mathrm{mg} / \mathrm{m}^{2}$; day 2: leucovorin $100 \mathrm{mg} / \mathrm{m}^{2}$ 2-hour intravenous infusion, 5-fluorouracil $400 \mathrm{mg} / \mathrm{m}^{2}$ "bolus" and 22-hour 5-fluorouracil intravenous infusion $600 \mathrm{mg} / \mathrm{m}^{2}$ every 14 days) versus patients treated with the LF regimen ("biweekly" regimen without oxaliplatin), a 50.7\% objective response rate was achieved versus $22.3 \%$ ( $p=0.0001)$, median time to progression was 9.0 versus 6.2 months ( $p=0.0003)$, and median overall survival time was $16.2 \mathrm{vs}$. 14.7 months $(p=0.12)$. Table 1 summarizes the results.

A randomized study by Tournigand et al. [11] compared the efficacy of first line sequential irinotecan-based therapy (FOLFIRI) and oxaliplatin-based therapy (FOLFOX 6) (day 1: oxaliplatin $100 \mathrm{mg} / \mathrm{m}^{2}$, leucovorin $200 \mathrm{mg} / \mathrm{m}^{2}$ 2-hour intravenous infusion, 5 -fluorouracil $400 \mathrm{mg} / \mathrm{m}^{2}$ "bolus" and 46-hour fluorouracil intravenous infusion $2400-3000$ mg/m² every 14 days) as second line therapy (group A) versus patients who received therapeutic regimens in the reversed order: FOLFOX 6 as first line therapy, and FOLFIRI regimen after disease progression (group B). Objective response rate, median time to disease progression and median overall survival were comparable in both these groups (there was a trend toward improved parameters of treatment efficacy in group A vs. group B). Table 2 summarizes the results.

Table 2. Efficacy of chemotherapy in group A in comparison to group B

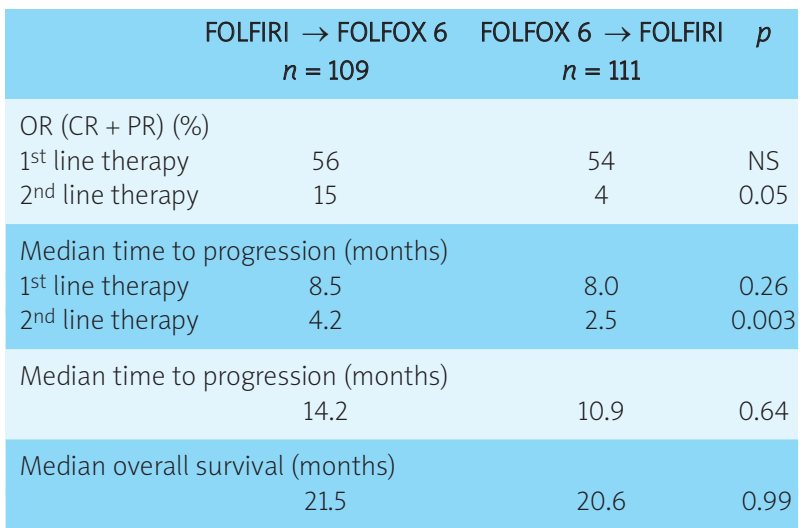


This study demonstrated much lower incidence of grade 3 and 4 side effects in the group of patients treated with the FOLFIRI regimen versus the group of patients receiving the FOLFOX regimen (53 vs. 74\%; $p=0.001$ ). Mucositis, nausea, vomiting, neutropenic fever and alopecia were observed more commonly in patients treated with chemotherapy with irinotecan, while neutropenia, thrombocytopenia and neurotoxicity were more common in patients treated with chemotherapy with oxaliplatin.

In summary, this study showed that irinotecan- and oxaliplatin-based chemotherapies have similar efficacy but different toxicity profiles: irinotecan predominantly causes cholinergic syndrome, while oxaliplatin mainly causes neurotoxicity (unfortunately there is no effective neuroprotective treatment for it) [9].

\section{Chemotherapy or chemotherapy with a biological agent as first line treatment for metastatic colorectal cancer?}

\section{Bevacizumab}

Bevacizumab is a recombined, humanized monoclonal IgG1 antibody against vascular endothelial growth factor (VEGF). It is $93 \%$ human and $7 \%$ murine. Bevacizumab inhibits endothelial proliferation and formation of abnormal blood vessels [12].

The efficacy of bevacizumab in combination with chemotherapy was confirmed in multiple randomized clinical trials. Addition of bevacizumab to the IFL regimen (irinotecan, 5-fluorouracil, leucovorin every 6 weeks), versus patients receiving only IFL chemotherapy as first line treatment for metastatic CRC, results in significant increase of objective response rate ( 44.8 vs. $34.8 \%, p=0.004$ ), prolongation of median time to progression (10.6 months vs. 6.2 months, $p \leq 0.001)$ and increased median overall survival (20.3 months vs. 15.6 months, $p<0.001)$ [13].

Slightly lower efficacy was reported following combination of bevacizumab with other chemotherapeutic regimens: - with FOLFOX-4/XELOX - significant prolongation of time to progression (9.4 vs. 8.0 months, $p=0.0023$ ) and insignificant improvement of overall survival (21.3 vs. 19.9 months, $p=0.077$ ) without increasing the objective response rate (47 vs. 49\%, $p=0.31$ ) [14],

- with 5 -fluorouracil and leucovorin (5-FU/FA every 6 weeks) - significant prolongation of median time to progression
(9.2 vs. 5.5 months, $p=0.0002$ ) and increase of objective response rate ( 26 vs. $15.2 \%, p=0.055$ ), and insignificant improvement of overall survival (16.6 vs. 12.9 months, $p=0.16$ ) [15],

- with capecitabine, significant prolongation of median time to progression (8.5 vs. 5.7 months, $p<0.0001$ ), and insignificant improvement of objective response rate (38 vs. 30\%), without prolongation of overall survival (18.4 vs. 19.1 months, $p=0.24$ ) [16]. Table 3 summarizes these studies.

Bevacizumab therapy was quite well tolerated. "Typical" bevacizumab side effects (hypertension, proteinuria, diarrhoea, thromboembolic events) were reported more often in patients treated with bevacizumab in combination with chemotherapy versus chemotherapy alone $[13,14]$.

Addition of a biological agent (bevacizumab) to chemotherapy significantly increases the efficacy of first line treatment for metastatic CRC. Irinotecan-based chemotherapy seems the optimal chemotherapy added to bevacizumab.

\section{Cetuximab}

Cetuximab is a chimeric (part murine, part human) monoclonal IgG1 antibody directed against the extracellular domain of the epidermal growth factor receptor (EGFR). Cetuximab inhibits cellular growth and proliferation and induces apoptosis [17]. Apart from the direct antitumour effect associated with its binding to RGFR, cetuximab also exerts indirect effects through initiation of an immune reaction associated with antibody-dependent cellular cytotoxicity [18].

Previous clinical studies resulted in the development of a predictive factor for efficacy of anti-EGFR monoclonal antibodies: the KRAS gene. Patients with an activating mutation in codon 12 or 13 of the KRAS gene were found to exhibit complete lack of clinical activity of cetuximab [19] and panitumumab [20].

Clinical activity of cetuximab in combination with chemotherapy as first line treatment of metastatic CRC was confirmed only in patients with wild-type K-Ras). Cetuximab in combination with irinotecan-based chemotherapy (FOLFIRI regimen), versus chemotherapy alone, significantly increased the complete response rate (57.3 vs. 39.7\%, $p<0.0001$ ), and prolonged time to progression (9.9 vs. 8.4

Table 3. Efficacy of bevacizumab in combination with chemotherapy in comparison to chemotherapy alone

\begin{tabular}{|c|c|c|c|c|}
\hline Regimen & $n$ & Response rate (\%) & $\begin{array}{l}\text { Median PFS } \\
\text { (months) }\end{array}$ & $\begin{array}{l}\text { Median OS } \\
\text { (months) }\end{array}$ \\
\hline $\begin{array}{l}\text { IFL } \\
\text { IFL + bevacizumab [13] }\end{array}$ & 813 & $\begin{array}{l}35 \\
45^{\star}\end{array}$ & $\begin{array}{l}6.2 \\
10.6^{*}\end{array}$ & $\begin{array}{l}15.6 \\
20.3^{*}\end{array}$ \\
\hline $\begin{array}{l}\text { 5FU/LV } \\
\text { 5FU/LV + bevacizumab [15] }\end{array}$ & 209 & $\begin{array}{l}15 \\
26^{\star}\end{array}$ & $\begin{array}{l}5.5 \\
9.2^{\star}\end{array}$ & $\begin{array}{l}12.9 \\
16.6\end{array}$ \\
\hline $\begin{array}{l}\text { XELOX/FOLFOX } \\
\text { XELOX/FOLFOX + bevacizumab [14] }\end{array}$ & 1401 & $\begin{array}{l}49 \\
47\end{array}$ & $\begin{array}{l}8.0 \\
9.4^{*}\end{array}$ & $\begin{array}{l}19.9 \\
21.3\end{array}$ \\
\hline $\begin{array}{l}\text { capecitabine } \\
\text { capecitabine + bevacizumab [16] }\end{array}$ & $\begin{array}{l}156 \\
157\end{array}$ & $\begin{array}{l}30 \\
38\end{array}$ & $\begin{array}{l}5.7 \\
8.5^{*}\end{array}$ & $\begin{array}{l}18.4 \\
19.1\end{array}$ \\
\hline
\end{tabular}


Table 4. Efficacy of cetuximab in combination with irinotecan-based chemotherapy in comparison to chemotherapy alone

\begin{tabular}{|c|c|c|c|}
\hline Wild-type $K$-Ras* & FOLFIRI & FOLFIRI + cetuximab & $p$-value \\
\hline$n$ & 350 & 316 & - \\
\hline response rate (\%) & 39.7 & 57.3 & $<0.0001$ \\
\hline median time to progression (months) & 8.4 & 9.9 & 0.0012 \\
\hline median overall survival (months) & 20 & 23.5 & 0.0094 \\
\hline KRAS mutation* & FOLFIRI & FOLFIRI + cetuximab & $p$-value \\
\hline$N$ & 183 & 214 & - \\
\hline response rate (\%) & 36.1 & 31.3 & 0.34 \\
\hline median time to progression (months) & 7.7 & 7.4 & 0.26 \\
\hline median overall survival (months) & 16.7 & 16.2 & 0.75 \\
\hline
\end{tabular}

*analysis of KRAS gene status was done retrospectively

months, $p=0.0012)$ and median overall survival time (23.5 vs. 20 months, $p=0.0094$ ). However, no effect of cetuximab on chemotherapy efficacy was found in patients with mutated KRAS [21]. Table 4 summarizes these results.

Results of the COIN trial, comparing oxaliplatin therapy (CAPOX regimen/FOLFOX regimen) in combination with cetuximab versus chemotherapy alone, presented at ECCO/ESMO 2009, did not meet the expectations. Only a significant increase of the objective response rate was achieved in a group of patients with wild-type $K$-Ras, treated with oxaliplatin and cetuximab versus patients treated with chemotherapy alone ( 59 vs. $50 \%, p=0.015$ ). However, no significant improvement of time to survival or median overall survival was achieved. In a group of patients with KRAS mutation, addition of cetuximab to oxaliplatin-based regimens resulted in insignificant shortening of median time to progression and median overall survival [22]. Table 5 summarizes the full results.

Cetuximab requires administration as weekly infusions, each preceded by premedication. Use of cetuximab with chemotherapy versus chemotherapy was associated with higher risk of serious side effects (grade 3 and 4) mani- festing as: diarrhoea (15.7 vs. $10.5 \%, p=0.008$ ), acne-like rash (16.2 vs. $0 \%, p<0.001)$ and serious infusion reactions (2.5 vs. $0 \%, p<0.001$ ). Intensity of skin lesions was associated with prolongation of median time to progression [23].

The above-presented clinical trials do not allow a definite conclusion as to which cetuximab-based chemotherapy regimen is more effective, due to difficulties in comparing the prospective COIN study with retrospective analyses of the CRYSTAL and OPUS studies. However, cetuximab therapy is associated with a significant worsening of quality of life related to "typical" cetuximab side effects and the requirement of weekly drug administration.

\section{Panitumumab}

Panitumumab is a fully humanized monoclonal lgG2 antibody directed, like cetuximab, against EGFR, with the same mechanism of action [20].

In the PRIME study [24], the combination of panitumumab with FOLFOX4 chemotherapy vs. chemotherapy alone, in a group of patients with the wild-type $K$-Ras gene,

Table 5. Efficacy of cetuximab in combination with oxaliplatin-based chemotherapy in comparison to chemotherapy alone

\begin{tabular}{|c|c|c|c|}
\hline Wild-type $K$-Ras* & FOLFOX/CAPOX & $\begin{array}{l}\text { FOLFOX/CAPOX + } \\
\text { cetuximab }\end{array}$ & $p$-value \\
\hline$N$ & 367 & 362 & - \\
\hline response rate (\%) & 50 & 59 & $<0.015$ \\
\hline median time to progression (months) & 8.6 & 8.6 & 0.60 \\
\hline median overall survival (months) & 17.9 & 17 & 0.68 \\
\hline KRAS mutation* & FOLFOX/CAPOX & $\begin{array}{l}\text { FOLFOX/CAPOX + } \\
\text { cetuximab }\end{array}$ & $p$-value \\
\hline$N$ & 268 & 297 & - \\
\hline response rate (\%) & 41 & 40 & 0.87 \\
\hline median time to progression (months) & 6.9 & 6.5 & 0.46 \\
\hline median overall survival (months) & 14.8 & 13.6 & 0.80 \\
\hline
\end{tabular}

*analysis of KRAS gene status was done retrospectively 
resulted in significant prolongation of median time to progression (9.6 vs. 8.0 months, $p=0.02$ ) and a non-significant increase of the objective response rate ( 55 vs. $48 \%$, $p=0.068)$. In a group of patients with a mutated $K$-Ras gene, addition of panitumumab to oxaliplatin-based chemotherapy resulted in a significant shortening of median time to progression and median overall survival (table 6).

Reported side effects related to panitumumab treatment included diarrhoea, hypomagnesaemia, and erythema. Two patients (<1\%) developed a serious (grade 3 ) infusion reaction.

Panitumumab therapy in combination with oxaliplatin is effective only in patients with the wild-type $K$-Ras gene. However, we must emphasize that analysis of KRAS gene status was performed retrospectively in this study, which reduces the significance of the results obtained in both groups of patients with the wild-type and mutated KRAS gene. Since this is a fully humanized antibody, no significant rate of serious infusion reactions was reported.

\section{Combination of chemotherapy with anti-VEGF and anti-EGFR as first line therapy for metastatic colorectal cancer}

Combined antineoplastic therapy - chemotherapy plus anti-VEGF and anti-EGFR therapy - was unsuccessful. Shortening of median time to progression and median overall survival was reported in the PACCE study, in a group of patients with wild-type $K$-Ras, who received chemotherapy (FOLFOX or FOLFIRI) in combination with bevacizumab and panitumumab versus patients treated without panitumumab. Similar results were obtained in a group of patients with KRAS gene mutation [25] (table 7 and 8).

Table 6. Efficacy of panitumumab in combination with oxaliplatin-based chemotherapy in comparison to chemotherapy alone

\begin{tabular}{|c|c|c|c|}
\hline Wild-type $K$-Ras* & FOLFOX4 & $\begin{array}{c}\text { FOLFOX4 + } \\
\text { panitumumab }\end{array}$ & $p$-value \\
\hline N & 331 & 325 & - \\
\hline response rate (\%) & 48 & 55 & 0.068 \\
\hline median time to progression (months) & 8.0 & 9.6 & 0.02 \\
\hline median overall survival (months) & 18.8 & not achieved & 0.16 \\
\hline KRAS mutation* & FOLFOX4 & $\begin{array}{c}\text { FOLFOX4 + } \\
\text { panitumumab }\end{array}$ & $p$-value \\
\hline$N$ & 219 & 221 & - \\
\hline response rate (\%) & 40 & 40 & 0.98 \\
\hline median time to progression (months) & 8.8 & 7.3 & 0.02 \\
\hline median overall survival (months) & 18.7 & 15.1 & 0.004 \\
\hline
\end{tabular}

Table 7. Efficacy of bevacizumab with or without panitumumab in combination with oxaliplatin- and irinotecan-based chemotherapy in wild-type $K$-Ras group

\begin{tabular}{|c|c|c|c|}
\hline Wild-type $K$-Ras* & $\begin{array}{c}\text { Oxaliplatin + } \\
\text { bevacizumab + } \\
\text { panitumumab }\end{array}$ & $\begin{array}{l}\text { Oxaliplatin + } \\
\text { bevacizumab }\end{array}$ & $\begin{array}{c}\text { HR } \\
95 \% \mathrm{Cl}\end{array}$ \\
\hline N & 201 & 203 & - \\
\hline response rate (\%) & 50 & 56 & - \\
\hline median time to progression (months) & 9.8 & 11.5 & $\begin{array}{c}1.36 \\
1.04-1.77\end{array}$ \\
\hline median overall survival (months) & 20.7 & 24.5 & $\begin{array}{c}1.89 \\
1.30-2.75\end{array}$ \\
\hline Wild-type $K-$ Ras $^{*}$ & $\begin{array}{c}\text { Irinotecan + } \\
\text { bevacizumab + } \\
\text { panitumumab }\end{array}$ & $\begin{array}{l}\text { Irinotecan + } \\
\text { bevacizumab }\end{array}$ & $\begin{array}{c}\mathrm{HR} \\
95 \% \mathrm{Cl}\end{array}$ \\
\hline$n$ & 57 & 58 & - \\
\hline response rate (\%) & 54 & 48 & - \\
\hline median time to progression (months) & 10 & 12.5 & $\begin{array}{c}1.50 \\
0.82-2.76\end{array}$ \\
\hline median overall survival (months) & not assessed & 19.8 & $\begin{array}{c}1.28 \\
0.50-3.25\end{array}$ \\
\hline
\end{tabular}


Table 8. Efficacy of bevacizumab with or without panitumumab in combination with oxaliplatin- and irinotecan-based chemotherapy in mutant KRAS group

\begin{tabular}{|c|c|c|c|}
\hline Wild-type $K-R a s^{*}$ & $\begin{array}{l}\text { Oxaliplatin + } \\
\text { bevacizumab + } \\
\text { panitumumab }\end{array}$ & $\begin{array}{l}\text { Oxaliplatin + } \\
\text { bevacizumab }\end{array}$ & $\begin{array}{c}\text { HR } \\
95 \% \mathrm{Cl}\end{array}$ \\
\hline$N$ & 135 & 125 & - \\
\hline response rate (\%) & 47 & 44 & - \\
\hline median time to progression (months) & 10.4 & 11 & $\begin{array}{c}1.25 \\
0.91-1.71\end{array}$ \\
\hline median overall survival (months) & 19.3 & 19.3 & $\begin{array}{c}1.02 \\
0.67-1.54\end{array}$ \\
\hline KRAS mutation* & $\begin{array}{c}\text { Irinotecan + } \\
\text { bevacizumab + } \\
\text { panitumumab }\end{array}$ & $\begin{array}{l}\text { Irinotecan + } \\
\text { bevacizumab }\end{array}$ & $\begin{array}{c}\mathrm{HR} \\
95 \% \mathrm{Cl}\end{array}$ \\
\hline$n$ & 47 & 39 & - \\
\hline response rate (\%) & 30 & 38 & - \\
\hline median time to progression (months) & 8.3 & 11.9 & $\begin{array}{c}1.19 \\
0.65-2.21\end{array}$ \\
\hline median overall survival (months) & 17.8 & 20.5 & $\begin{array}{c}2.14 \\
0.82-5.59\end{array}$ \\
\hline
\end{tabular}

*analysis of KRAS gene status was done retrospectively

Furthermore, combination of chemotherapy and anti-VEGF and anti-EGFR therapy was associated with higher incidence of grade 3 and 4 serious side effects: in a group of patients treated with oxaliplatin, bevacizumab and panitumumab chemotherapy versus a group of patients not receiving panitumumab, higher incidence of the following was observed: skin toxicity (36 vs. $1 \%$ ), diarrhoea ( 24 vs. $13 \%$ ), infection (19 vs. 10\%) and pulmonary embolism (6 vs. 4\%) [25].

Similar results were obtained in the clinical study CAIRO 2 [26]: non-significant shortening of median time to progression and median overall survival was obtained in a group of patients with the wild-type $K$-Ras gene, treated with the
CAPOX regimen (capecitabine + oxaliplatin) with bevacizumab and cetuximab versus a group of patients treated without cetuximab, while significant shortening of median time to progression and median overall survival was obtained in a group of patients with a mutated KRAS gene (table 9).

Addition of cetuximab to chemotherapy and bevacizumab was associated with increased incidence of grade 3 and 4 serious side effects ( 817 vs. $73.2 \%, p=0.006$ ) [26].

The above-presented clinical studies indicate that a combination of anti-EGFR and anti-VEGF therapy plus chemotherapy should not be recommended in the treatment of patients with metastatic CRC.

Table 9. Efficacy of bevacizumab with or without cetuximab in combination with CAPOX chemotherapy

\begin{tabular}{|c|c|c|c|}
\hline Wild-type $K$-Ras ${ }^{*}$ & $\begin{array}{c}\text { CAPOX+ } \\
\text { bevacizumab }\end{array}$ & $\begin{array}{c}\text { CAPOX + } \\
\text { bevacizumab+ } \\
\text { cetuximab }\end{array}$ & $p$-value \\
\hline$N$ & 156 & 158 & - \\
\hline response rate (\%) & 50 & 61.4 & 0.06 \\
\hline median time to progression (months) & 10.6 & 10.5 & 0.30 \\
\hline median overall survival (months) & 22.4 & 21.8 & 0.64 \\
\hline KRAS mutation* & $\begin{array}{c}\text { CAPOX + } \\
\text { bevacizumab }\end{array}$ & $\begin{array}{c}\text { CAPOX + } \\
\text { bevacizumab + } \\
\text { cetuximab }\end{array}$ & $p$-value \\
\hline$n$ & 108 & 98 & - \\
\hline response rate (\%) & 59 & 46 & 0.03 \\
\hline median time to progression (months) & 12.5 & 8.1 & 0.003 \\
\hline median overall survival (months) & 24.9 & 17.2 & 0.03 \\
\hline
\end{tabular}




\section{Chemotherapy with a biological agent as second line therapy for metastatic colorectal cancer}

\section{Panitumumab}

A clinical study presented at ECCO/ESMO 2009 [27] compared the efficacy of the chemotherapeutic regimen FOLFIRI as the sole therapy or in combination with panitumumab as second line therapy for metastatic CRC after "exposure" to oxaliplatin and bevacizumab. Significant prolongation of median time to progression and insignificant prolongation of overall survival were obtained in a group of patients with wild-type $K$-Ras versus patients treated with only chemotherapy. A group of patients with KRAS gene mutation did not benefit from addition of panitumumab to che motherapy (table 10).

Observed anti-EGFR treatment related toxicities included erythema, diarrhoea, and hypomagnesaemia. A serious (grade 3 ) infusion reaction occurred in only two $(<1 \%)$ patients.

Unfortunately, the final results of this study have not been published, and as in other anti-EGFR studies, analysis of KRAS gene status was only retrospective.

\section{Bevacizumab}

A phase 3 study [28] assessed the efficacy of FOLFOX4 chemotherapy with or without bevacizumab as second line treatment for CRC. A key inclusion criterion was previous irinotecan- and fluoropyrimidine derivative-based chemotherapy. Significant improvement of median time to progression (7.3 vs. 4.7 months $p<0001)$, median overall survival (12.9 vs. 10.8 months, $p=0.0011$ ) and objective response rate ( 22.7 vs. $8.6 \%, p<0.0001)$ was achieved in a group of patients receiving chemoimmunotherapy (bevacizumab + FOLFOX4) vs. only chemotherapy (FOLFOX4). Higher incidence of hypertension, vomiting and bleeding was reported in the group of patients receiving chemoimmunotherapy.
Panitumumab with irinotecan-based chemotherapy (FOLFIRI regimen) as second line therapy can be used only in patients with the wild-type KRAS gene, after failure of oxaliplatin- and/or bevacizumab-based chemotherapy, while bevacizumab in combination with oxaliplatin (FOLFOX) can be used in patients after failure of treatment with irinotecan and fluoropyrimidine derivatives.

\section{Anti-EGFR therapy in patients after failure of treatment with irinotecan, oxaliplatin and fluoropyrimidine derivatives}

\section{Panitumumab}

Amado et al. [20] compared the efficacy of panitumumab monotherapy and best supportive treatment (BST) in patients after failure of irinotecan, oxaliplatin and fluoropyrimidine derivatives. Use of panitumumab in a group of patients with the wild-type $K$-Ras gene was associated with significant prolongation of median time to progression (12.3 vs. 7.3 weeks, $p<0.0001$ ), without significant prolongation of median overall survival (8.1 vs. 7.6 months; HR - 0.99; $95 \% \mathrm{Cl}$ : 0.75-1.29). In a group of patients with KRAS gene mutation, panitumumab versus BST did not improve median time to progression (7.4 vs. 7.3 weeks; HR - 0.99, $95 \% \mathrm{Cl}: 0.73-1.36$ ) or median overall survival (4.9 vs. 4.4 months; HR - 1.02, 95\% Cl: 0.75-1.39). Panitumumab increased the incidence of adverse effects: diarrhoea, skin toxicity and hypomagnesaemia.

\section{Cetuximab}

Cetuximab is a second drug with confirmed activity as monotherapy in a group of patients with the wild-type KRAS gene after failure of irinotecan, oxaliplatin, 5-fluorouracil/capecitabine therapy $[29,30]$. Significant prolongation of median time to progression (3.7 vs. 1.9 months, $p<0.001$ ) and median overall survival (9.5 vs. 4.8 months, $p<0.001)$ was reported in a group of patients with the wild-

Table 10. Efficacy of panitumumab in combination with irinotecan-based chemotherapy (FOLFIRI) in comparison to chemotherapy alone in second line treatment of metastatic colorectal cancer

\begin{tabular}{|c|c|c|c|}
\hline Wild-type $K-$ Ras $^{*}$ & FOLFIRI & $\begin{array}{c}\text { FOLFIRI + } \\
\text { panitumumab }\end{array}$ & $p$-value \\
\hline N & 294 & 303 & - \\
\hline response rate (\%) & 10 & 35 & - \\
\hline median time to progression (months) & 3.9 & 5.9 & 0.004 \\
\hline median overall survival (months) & 12.5 & 14.5 & 0.115 \\
\hline KRAS mutation* & FOLFIRI & $\begin{array}{c}\text { FOLFIRI + } \\
\text { panitumumab }\end{array}$ & $p$-value \\
\hline$n$ & 248 & 238 & - \\
\hline response rate (\%) & 14 & 13 & - \\
\hline median time to progression (months) & 4.9 & 5.0 & NS \\
\hline median overall survival (months) & 11.1 & 11.8 & NS \\
\hline
\end{tabular}

NS - not significant

*analysis of KRAS gene status was done retrospectively 
Table 11. Comparison of panitumumab to cetuximab after chemotherapy based on irinotecan, oxaliplatin and fluoropyrimidines in wild-type group

\begin{tabular}{lcc} 
& Cetuximab $[29,30]$ & Panitumumab [20] \\
\hline Response rate & $12.8 \%$ & $17 \%$ \\
\hline $\begin{array}{l}\text { Median time } \\
\text { to progression }\end{array}$ & 3.7 (months) & 12.3 (weeks) \\
$\begin{array}{l}\text { Median overall } \\
\text { survival }\end{array}$ & 9.5 (months) & 8.1 (months) \\
$\begin{array}{l}\text { Frequency of } \\
\text { administration }\end{array}$ & $1 \times$ week & $1 \times 2$ weeks \\
\hline $\begin{array}{l}\text { Premedication } \\
\text { required }\end{array}$ & YES & NO \\
Infusion & $20.5 \%$ & 1 patient \\
reactions & $4.5 \%$ (grade 3 and 4) & $0 \%$
\end{tabular}

type $K$-Ras gene treated with cetuximab vs. BST. No significant prolongation of median time to progression (1.8 vs. 1.8 months, $p=0.96$ ) or median overall survival (4.5 vs. 4.6 months, $p=0.89$ ) was reported in a group of patients with a mutated KRAS gene treated with cetuximab vs. BST. There was higher incidence of serious grade 3 and 4 side effects ("typical" for cetuximab) manifesting as serious infusion reactions (4.5 vs. $0 \%, p<0.001$ ), skin lesions (11.8 vs. $0.4 \%$, $p<0.001$ ) and hypomagnesaemia (5.8 vs. $0 \%, p<0.001$ ). Skin toxicity was correlated with prolongation of median overall survival: for patients without skin lesions - 2.6 months; for patients with grade 1 toxicity -4.8 months; and for patients with grade 2 toxicity -8.4 months $(p<0.001)$. A comparison of drugs is summarized in table 11.

Both panitumumab and cetuximab seem to be more active in a group of patients with wild-type $K$-Ras after failure of previous irinotecan, oxaliplatin and fluoropyrimidine derivatives based therapy. However, this requires confirmation in prospective clinical trials.

Recently, enormous progress has been made in the systemic, palliative treatment of colorectal cancer. The launch of new "targeted" drugs prolonged the median time to progression and median overall survival. The order of specific therapies to provide the greatest benefit with the lowest possible side effects remains to be determined.

The conducted clinical studies indicated that irinotecanand oxaliplatin-based first line palliative chemotherapies were comparable with regard to efficacy. Oxaliplatin-based chemotherapy versus irinotecan-based chemotherapy has a slightly different and presumably less favourable toxicity profile (neurotoxicity). Irinotecan combined with bevacizumab as first line therapy for metastatic CRC seems to be a more beneficial therapeutic option than a combination of oxaliplatin and bevacizumab.

Second line therapy should be based on chemotherapy containing oxaliplatin. We have two regimens: FOLFOX and its variants, and XELOX. Their efficacy is comparable, with lower incidence of grade 3 and 4 side effects in patients treated with XELOX chemotherapy [31].

Combination of cetuximab and irinotecan-based chemotherapy exhibited some activity as first line therapy for metastatic CRC, predominantly in prolonging time to progression. However, this regimen is associated with an unfavourable toxicity profile, mainly skin toxicity that markedly worsens quality of life and markedly reduces professional and everyday patient activity. Furthermore, cetuximab requires weekly administration and its efficacy is related to skin toxicity. Such therapy is possible only in patients with wild-type K-Ras.

Anti-EGFR therapy as first line therapy for metastatic CRC essentially cannot be given after failure of previous irinotecan, oxaliplatin and fluoropyrimidine derivatives based therapy. Therefore we lose one of the possible therapeutic options.

Negative effects of anti-EGFR and anti-VEGF therapies were observed with combinations of bevacizumab and cetuximab or panitumumab; therefore such drug combinations are not allowed.

Absolute benefits of anti-EGFR therapies seem to be greater in subsequent lines of therapy, while they seem to be reduced for bevacizumab in subsequent lines of therapy.

Therefore, options of systemic therapy for metastatic CRC, after failure of previous irinotecan, oxaliplatin and fluoropyrimidine derivatives based therapy in patients with wild-type $K$-Ras, include cetuximab or panitumumab monotherapy. These drugs have comparable efficacy, with slightly better tolerance of panitumumab, in particular with regard to infusion reactions. Definite establishment of superiority of one of these drugs will be possible when the results of a clinical trial directly comparing panitumumab and cetuximab are available.

Of course, patients with poorer general condition, with significant comorbidities or contraindications to particular therapies, require adjustment of therapeutic management to the individual patient's needs. This includes a possible decision to provide only the best supportive care.

\section{References}

1. Steward BW, Kleihues P. World cancer report. Lyon, France: IARC Press 2003; 198.

2. Nowacki M, Bielecki K, Drews M. Nowotwory jelita grubego. In: Zasady diagnostyki i chirurgicznego leczenia nowotworów w Polsce. Andrzej W. Szawłowski, Jacek Szmidt (ed.). Fundacja-Polski Przegląd Chirurgiczny; Warszawa 2003; 226.

3. Wojciechowska U, Didkowska J, Zatoński W. Nowotwory złośliwe w Polsce w 2006 roku. Centrum Onkologii - Instytut im. Marii Skłodowskiej-Curie 2008. Chapter 8; 49-86.

4. Adjei AA. A review of the pharmacology and clinical activity of new chemotherapy agents for the treatment of colorectal cancer. J Clin Pharmacol 1999; 48: 265-77.

5. Omyła-Staszewska J, Deptała A. Inhibitory topoizomerazy I unikalna grupa leków przeciwnowotworowych. Współcz Onkol 2003; 7: 45-53.

6. Saltz BL, Cox VJ, Blanke C et al. Irinotecan plus fluorouracil and Leukovorin for metastatic colorectal cancer. N Engl J Med 2000; 343: 905-14.

7. Douillard JY, Cunningham D, Roth AD, et al. (2000) Irinotecan com bined with fluorouracil compared with fluorouracil alone as first line treatment for metastatic colorectal cancer: a multicenter randomized trial. Lancet 2000; 355: 1041-7.

8. Gluzman A, Rubinov K, Mermershtain W, et al. Retrospective com parison of two different schedules of Irinotecan, 5-fluorouracil, and folinic acid in previously untreated patients with advanced colorectal carcinoma: a single institution experience. J Chemother 2007; 19: 739-43. 
9. Saif MW, Reardon J. Management of oxaliplatin-induced peripheral neuropathy. Ther Clin Risk Management 2005; 1: 249-58.

10. De Gramont A, Figer A, Seymour M, et al. Leucovorin and fluorouracil with or without oxaliplatin as first-line treatment in advanced colorectal cancer. J Clin Oncol 2000; 18: 2938-47.

11. Tournigand C, André T, Achille E, et al. Folfiri followed by FOLFOX6 or reverse sequence in advanced colorectal cancer: a randomized GERCOR study. J Clin Oncol 2004; 22: 229-37.

12. Ferrara N, Hillan KJ, Gerber HP, et al. Discovery and development of bevacizumab, an anti-VEGF antibody for treating cancer. Nat Rev Drug Discov 2004; 3: 391-400.

13. Hurwitz H, Fehrenbacher L, Novotny W, et al. Bevacizumab plus irinotecan, fluorouracil, leucovorin for metastatic colorectal cancer. N Eng J Med 2004; 350: 2335-232.

14. Saltz LB, Clarke S, Diaz-Rubio E, et al. Bevacizumab in combination with oxaliplatin-based chemotherapy as first-line therapy in metastatic colorectal cancer: a randomized phase III study. I Clin Oncol 2008; 26: 2013-9

15. Kabbinavar FF, Schulz J, McCleod M, et al. Addition of bevacizumab to bolus fluorouracil and leucovorin in first-line metastatic colorectal cancer: results of a randomized phase II trial. J Clin Oncol 2005; 23: 3697-705.

16. Tebbutt NC, Gebski V, Wilson K, et al. International randomized phase III study of capecitabine (Cap), bevacizumab (Bev), and mit omycin C (MMC) in first-line metastatic colorectal cancer (mCRC) Final results of the AGITG MAX trial. J Clin Oncol 2009; 27: 15s, (suppl; abstr. 4023)

17. Li S, Schmitz KR, Jeffrey PD, et al. Structural basis for inhibition of the epidermal growth factor receptor by cetuximab. Cancer cell 2005; 7: 301-11.

18. Kurai J, Chikumi H, Hashimoto K, et al. Antibody- dependent cellular cytotoxicity mediated by cetuximab against lung cancer cell lines. Clin Cancer Res 2007; 13: 1552-61.

19. Ličvre A, Bachet JB, Boige V, et al. KRAS mutation as an independent prognostic factor in patients with advanced colorectal cancer treated with cetuximab. J Clin Oncol 2008; 26: 374-9.

20. Amado RG, Wolf M, Peeters $M$, et al. Wild-type KRAS is required for panitumumab efficacy in patients with metastatic colorectal cancer. J Clin Oncol 2008; 26: 1626-34.

21. Van Cutsem E, Rougier P, Köhne CH. A meta-analysis of the CRYS TAL and OPUS studies combining cetuximab with chemotherapy (CT) as 1st-line treatment for patients (pts) with metastatic colorectal cancer (mCRC): Results according to KRAS and BRAF mutation status. ECCO-ESMO 2009; Abstr. No:6.077.

22. Maughan T, Adams RA, Smith CG, et al. Addition of cetuximab to oxaliplatin-based combination chemotherapy (CT) in patients with KRAS wild-type advanced colorectal cancer (ACRC): a randomized superiority trial (MRC COIN).ECCO/ESMO 2009; Abstr. No. 6LBA

23. Van Cutsem E, Köhne C-H, Hitre E, et al. Cetuximab and chemotherapy as initial treatment for metastatic colorectal cancer. N Engl J Med 2009; 360: 1408-17

24. Douillard J, Siena S, Cassidy J, et al. Randomized phase III study of panitumumab with FOLFOX4 compared to FOLFOX4 alone as 1stline treatment (tx) for metastatic colorectal cancer (mCRC): the PRIME trial. Eur J Cancer 2009; Suppl. (abstr. No. 10LBA) 7: 6.

25. Hecht JR, Mitchell E, Chidiac T, et al. A randomized phase IIIb trial of chemotherapy, bevacizumab, and panitumumab compared with chemotherapy and bevacizumab alone for metastatic colorectal cancer. J Clin Oncol 2009; 27: 672-80.

26. Tol J, Koopman M, Cats A, et al. Chemotherapy, bevacizumab and cetuximab in metastatic colorectal cancer. N Engl J Med 2009; 360: 563-72.

27. Peeters $m$, Price T, Hotko Y, et al. Randomized phase 3 study of panitumumab with FOLFIRI vs FOLFIRI alone as second-line treatment (tx) in patients (pts) with metastatic colorectal cancer (mCRC). Eur J Cancer 2009; Suppl. (abstr. No. 14LBA), 7: 10.

28. Giantonio BJ, Catalano PJ, Meropol NJ, et al. (2007) Bevacizumab in combination with oxaliplatin, fluorouracil, and leucovorin (FOLFOX4) for previously treated metastatic colorectal cancer: results from the Eastern Cooperative Oncology Group Study E3200. J Clin Oncol 2007; 25: 1539-44.
29. Jonker DJ, O'Callaghan CJ, Karapetis CS, et al. Cetuximab for the treatment of colorectal cancer. N Engl J Med 2007; 357: 2040-8.

30. Karapetis CS, Khambata-Ford, Jonker DJ, et al. K-ras mutations and benefit from cetuximab in advanced colorectal cancer. N Engl J Med 2008; 359: 1757-65.

31. Rothenberg ML, Cox JV, Butts C, et al. Capecitabine plus oxaliplatin (XELOX) versus 5-fluorouracil/folinic acid plus oxaliplatin (FOLFOX-4) as second-line therapy in metastatic colorectal cancer: a randomized phase III noninferiority study. Ann Oncol 2008; 19: 1720-1726.

\section{Address for correspondence}

Rafał Stec, MD, PhD

Department of Oncology

Military Institute of Health Services

128 Szaserów St.

00-909 Warsaw, Poland

Phone/fax: +48 226818437

e-mail: drrafals@wp.pl 